\title{
Effect of abdominal vagotomy of the pregnant rat on LH and progesterone concentrations and fetal resorption
}

\author{
I. E. Lawrence, Jr, H. W. Burden and T. M. Louis \\ Department of Anatomy, School of Medicine, East Carolina University, Greenville, \\ North Carolina 27834, U.S.A.
}

\begin{abstract}
Summary. Abdominal vagotomy on Day 8 of pregnancy in rats decreased the number of live fetuses at Day 16 and increased the number of resorbing fetuses. The activity of $\Delta^{5}-3 \beta$-hydroxysteroid dehydrogenase ( $3 \beta$-HSD) in the corpus luteum and interstitial gland, $\mathrm{LH}$ and progesterone values in plasma and progesterone values in ovarian tissue were all lower in vagotomized rats than in sham-operated controls. Ovarian PGF levels were not affected. We suggest that these effects were caused by a direct effect of vagotomy on LH secretion which in turn lowers 3B-HSD activity and progesterone levels in ovarian tissue and plasma, leading to fetal resorption.
\end{abstract}

\section{Introduction}

Much information is available concerning the innervation of the rat ovary, but the importance of the parasympathetic supply remains controversial and poorly understood. One reason for this is that the thiocholine technique (Koelle, 1955; Karnovsky \& Roots, 1964) used to study ovarian acetylcholinesterase (AChE)-positive nerves (Bulmer, 1965; Jacobowitz \& Wallach, 1967; Jordan, 1970; Chaffee, 1974; Lawrence \& Burden, 1976) does not identify parasympathetic cholinergic nerves exclusively because AChE activity is present in sensory (Koelle, 1955), adrenergic (Koelle, 1955; Jacobowitz \& Koelle, 1965; Burn \& Rand, 1965), and post-ganglionic parasympathetic nerves.

Hill (1962) reported that parasympathetic innervation to the rodent ovary was via the vagus and that trans-thoracic vagotomy in the rat caused disturbances of the oestrous cycle. At autopsy, the ovaries were enlarged because of an increased number of large corpora lutea and the number of follicles with a large antrum was low. However, the interpretation of these observations was difficult because of the severe debilitating effects of trans-thoracic vagotomy. In the present study we have examined the effects of abdominal vagotomy in the pregnant rat.

\section{Materials and Methods}

\section{Animals}

The rats were obtained from ARS/Sprague-Dawley (Madison, Wisconsin). The oestrous cycles of nulliparous females were monitored daily by examination of vaginal lavages and females in prooestrus were placed with males of proven fertility. The morning on which a copulatory plug or spermatozoa in the lavage were found was designated Day 1 of pregnancy. Parturition normally occurs on Day 22 in our rat colony. On Day 8 of pregnancy, rats were randomly assigned to a control (sham-operation) or vagotomy group. All animals were given atropine sulphate $(1 \mathrm{mg} / \mathrm{kg}$ : Nutritional Biochemical Corporation, Cleveland, Ohio) s.c. at least $30 \mathrm{~min}$ before induction of anaesthesia by i.p. injection of chloral hydrate $(300 \mathrm{mg} / \mathrm{kg}$ : Mallinckrodt, Incorporated, St. Louis, Missouri). The 
uterus was exposed by laparotomy and the presence of decidual swellings confirmed. In the control group, the anterior and posterior vagal trunks were viewed but not touched. In the vagotomy group, the liver was gently reflected, the oesophagus exposed, and the anterior and posterior vagal trunks were cut with fine forceps. A prophylactic dose of penicillin G (10000 units) was given i.m. and the rats allowed to recover. Recovery was uneventful and the rats appeared normal. On Day 16 of pregnancy, the rats were lightly anaesthetized with ether and again laparotomized. The number and condition of fetuses and implantation sites were recorded, and blood was withdrawn from the abdominal aorta into heparinized syringes. The animals were then killed. The blood was immediately centrifuged at $4^{\circ} \mathrm{C}$ and plasma was stored at $-60^{\circ} \mathrm{C}$ until analysis. One ovary from each rat was immersed in a BEEM capsule containing OCT compound (Ames Company, Elkhart, Indiana), frozen rapidly in a solid $\mathrm{CO}_{2}$-acetone mixture, and stored at $-20^{\circ} \mathrm{C}$. The remaining ovary from each rat was frozen on solid $\mathrm{CO}_{2}$, freeze dried and the powder stored at $-60^{\circ} \mathrm{C}$ until analysis.

\section{Histochemistry}

The presence of $\Delta^{5}-3 \beta$-hydroxysteriod dehydrogenase ( $3 \beta$-HSD) activity in the corpora lutea and interstitial cells was determined. Sections $(12 \mu \mathrm{m})$ of the whole ovary were cut at $-20^{\circ} \mathrm{C}$ with a Slee cryostat and collected on albumin-treated slides, air dried, and incubated at $37^{\circ} \mathrm{C}$ for $3 \mathrm{~h}$ in a medium consisting of $20 \mathrm{ml} 0 \cdot 1 \mathrm{M}$-Tris buffer, $\mathrm{pH} \mathrm{7.4,10} \mathrm{mg} \mathrm{nitro-blue} \mathrm{tetrazolium,} 20 \mathrm{mg}$ NAD and $2 \mathrm{mg}$ pregnenolone dissolved in $0.5 \mathrm{ml} \mathrm{N}, \mathrm{N}$-dimethyl formamide. Control incubations were carried out concurrently with medium lacking the steroid substrate (substrate controls). The presence of tissue $\mathrm{NADH}$ diaphorase, necessary for transferring hydrogen from the dehydrogenase reaction to tetrazolium for formazan precipitation, was verified by incubating sections for $15 \mathrm{~min}$ in a medium containing buffer, NADH and nitro-blue tetrazolium (diaphorase controls). After all incubations, the sections were washed, fixed in buffered formalin and selected slides were lightly counterstained with neutral red (Blaha \& Leavitt, 1970).

The density of the diformazan reaction product was assessed on sections without counterstain with a Zeiss MPM $01 \mathrm{~K}$ photometer unit fitted on a Zeiss Photomicroscope II.

The photometer was calibrated to $100 \%$ transmission ( 0.000 absorbance) at $580 \mathrm{~nm}$ with a substrate control (blank) slide. Absorbance values from slides with reaction product were subsequently read directly from the amplifier and recorded for 16 random sections for each animal (eight sections/ slide, 2 slides/ovary) by an unbiased observer.

\section{LH assay}

Plasma LH was determined by the radioimmunoassay described by Niswender, Midgely, Monroe \& Reichert (1968). All samples were measured in duplicate and the measured values were averaged if the $\%$ bindings agreed within $5 \%$; otherwise, the measurements were repeated. The coefficients of variation within and between assays were 11.2 and $14.3 \%$, respectively. The sensitivity of the assay was $1 \mathrm{ng} / \mathrm{ml}$. The results are expressed as ng equivalents of NIAMDD-LH-RP1.

\section{Assay of prostaglandin and progesterone in ovaries and plasma}

Each freeze-dried and ground ovary (average $7.46 \mathrm{mg}$ ) was extracted with $5 \mathrm{ml}$ petroleum ether to remove progesterone and inactive lipids. The ovarian tissue was then re-extracted with $5 \mathrm{ml}$ diethyl ether acidified with $1 \mathrm{~N}$-acetic acid ( $\mathrm{pH} \mathrm{3} \cdot 1)$ to remove the prostaglandins (PGs). An internal standard of $\left[{ }^{3} \mathrm{H}\right] \mathrm{PGF}(3000 \mathrm{ct} / \mathrm{min})$ (sp. act. $178 \mathrm{Ci} / \mathrm{mmol}$ : New England Nuclear Corporation, Boston, Massachusetts) and $\left[{ }^{3} \mathrm{H}\right]$ progesterone $(3000 \mathrm{ct} / \mathrm{min})$ (sp. act. $110 \mathrm{Ci} / \mathrm{mmol}$ : New England Nuclear) was included in each sample and recovery for progesterone and PGF was 70-90\%. After extraction of progesterone, the petroleum ether was evaporated, and the residue resuspended in $0.2 \mathrm{ml}$ iso-octane. The progesterone was separated by celite microcolumn chromatography as described by Brenner, 
Gurrero, Cekan \& Diczfalusy (1973). The effluent was dried under nitrogen and then resuspended in $1 \mathrm{ml} 0.01 \mathrm{M}$-phosphate-buffered $\mathrm{NaCl}$ containing $1 \%$ gelatin $(\mathrm{pH} 7 \cdot 1)$. Duplicate aliquots amounting to $0.01 \mathrm{ml}$ of the total were used for radioimmunoassay. For PGF, the acidified diethyl ether extract was dried and then resuspended in $1 \mathrm{ml}$ phosphate-buffered saline and $0.1 \mathrm{ml}$ aliquots were used for radioimmunoassay and recovery determinations.

Plasma samples $(0.1 \mathrm{ml})$ were extracted for $5 \mathrm{~min}$ with 5 volumes of light petroleum ether to extract progesterone after addition of $3000 \mathrm{ct} / \mathrm{min}\left[{ }^{3} \mathrm{H}\right]$ progesterone as the internals tandard. The petroleum ether extract was then dried under nitrogen and prepared as previously described (Challis, Davies \& Ryan, 1973; Brenner et al., 1973). PGF and progesterone standards (10-500 pg of each), plasma samples and tissue extracts were measured by radioimmunoassays. The progesterone assay was that described by Challis et al. (1973) except that the antiserum was prepared against 200-oxime-progesterone conjugated with human serum albumin. The specificity of the antiserum was tested in 4 separate determinations. At a dilution of $1: 2500$ and $50 \%$ binding the cross-reactivities were $10 \%$ for $20 \alpha$-hydroxypregn-4-en-3-one, $4 \%$ for $17 \alpha$-hydroxyprogesterone, $3 \%$ for testosterone, $2 \%$ for androstenedione and $<1 \%$ for all other hormones. These cross-reactions were not important because progesterone was completely separated by the celite chromatography system used. The recovery of known amounts of labelled progesterone from plasma was 70-90\% $(n=10)$ and that of unlabelled steroid from water and control plasma was $94-102 \%(n=10)$. The coefficients of variation withinand between-assays were 9.0 and $9.6 \%$ respectively. The sensitivity was $0.5 \mathrm{ng} / \mathrm{ml}$.

Plasma PGF values were measured by the radioimmunoassay described by Stellflug, Louis, Hafs $\&$ Seguin (1975). The coefficients of variation within and between assays were 8.9 and $10.1 \%$ respectively and the sensitivity was $150 \mathrm{pg} / \mathrm{ml}$.

\section{Statistics}

All results were assessed by one-way analysis of variance after ascertaining that they were homogeneous.

\section{Results}

Fetuses

By using the fetal heart beat to identify live fetuses, the litter sizes shown in Table 2 were obtained. Vagotomy reduced the number of live fetuses by more than $50 \%$.

Table 1. Mean \pm s.e.m. photometric absorbance values* of the $3 \beta-H S D$ reaction product in ovaries removed from rats on Day 16 of pregnancy

\begin{tabular}{lccc}
\hline & $\begin{array}{c}\text { No. of } \\
\text { readings }\end{array}$ & Corpus luteum & Interstitial gland \\
\hline Sham control & 113 & $0.205 \pm 0.009$ & $0.064 \pm 0.004$ \\
Vagotomy & 99 & $0.192 \pm 0.007$ & $0.059 \pm 0.005$ \\
\hline
\end{tabular}

* Absorbance values were read directly from the amplifier after calibration to 0 absorbance with a substrate control slide (see Materials and Methods).

\section{Histochemistry}

NADH diaphorase was demonstrated in the interstitial gland and corpora lutea of animals in the control and vagotomy groups. Ovarian tissues exposed to media without the pregnenolone substrate were negative, while those incubated with the substrate had high densities of diformazan reaction 


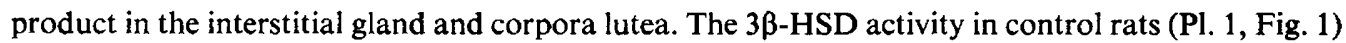
was similar to that previously reported for 14-day-pregnant animals (Burden \& Lawrence, 1977a), but was reduced in the vagotomized rats (Pl. 1, Fig. 2). Photometric readings of the absorbance of the diformazan corresponded to the visual impressions of density (Table 1), but the reduced activity in the vagotomized animals was not significant.

\section{Hormone concentrations}

$L H$. Plasma $\mathbf{L H}$ values in the control rats were in the range previously reported for Day-16 pregnant rats (Morishige, Pepe \& Rothchild, 1973) but those in the vagotomized rats were too low to measure (Table 2).

Progesterone. Vagotomy resulted in a significant reduction of plasma and ovarian progesterone levels (Table 2).

$P G F$. Vagotomy had no measurable effect on ovarian PGF concentrations.

Table 2. Effects (mean \pm s.e.m.) of vagotomy on Day 8 of pregnancy in rats (no. in parentheses) on fetal condition, $\mathrm{LH}$, progesterone and prostaglandin $\mathrm{F}$ at Day 16 of pregnancy

\begin{tabular}{lcr}
\hline & Sham-operated (15) & Vagotomized (13) \\
\hline No. of live fetuses & $9 \cdot 0 \pm 0.9$ & $4 \cdot 3 \pm 1 \cdot 2^{*}$ \\
No. of fetuses dead or resorbing & $1 \cdot 0 \pm 0.4$ & $3 \cdot 6 \pm 1 \cdot 1^{*}$ \\
Plasma LH $(\mathrm{ng} / \mathrm{ml})$ & $2 \cdot 4 \pm 0 \cdot 6$ & $1 \cdot 0 \pm 0 \cdot 0^{*} \pm$ \\
Ovarian progesterone $(\mathrm{ng} / 10 \mathrm{mg}) \dagger$ & $297 \cdot 1 \pm 21 \cdot 7$ & $154 \cdot 7 \pm 39 \cdot 8^{*}$ \\
Plasma progesterone $(\mathrm{ng} / \mathrm{ml})$ & $139 \cdot 4 \pm 9 \cdot 2$ & $101 \cdot 2 \pm 16 \cdot 0^{*}$ \\
Ovarian prostaglandin F $(\mathrm{pg} / 10 \mathrm{mg})$ & $563 \cdot 5 \pm 100 \cdot 1$ & $576.6 \pm 118 \cdot 1$ \\
\hline
\end{tabular}

* Significantly different from value for sham-operated animals $(P<0.05)$.

$\dagger$ These values were based on determinations for 1 ovary of each of 5 sham-operated and 4 vagotomized rats.

$\ddagger$ LH values were below the sensitivity $(1 \mathrm{ng} / \mathrm{ml})$ of the assay in all 13 vagotomized animals and 9 of 15 sham-operated animals. All values too low to measure were assigned a value of 1 for purposes of statistical comparison.

\section{Discussion}

Vagotomy during pregnancy in the rat results in a decreased number of live fetuses at Day 16, lowered plasma LH and progesterone concentrations and decreased ovarian progesterone levels. The concomitant hormone changes suggest that the fetal resorption is unlikely to be due to a direct effect of vagotomy on the uterus. Interruption of the vagus could therefore directly produce alterations in ovarian function or indirectly affect ovarian function by influencing LH release. Because LH can maintain pregnancy in the rat up to Day 12 by stimulating ovarian steroidogenesis and deprivation of $\mathrm{LH}$ for very short periods, e.g. $2-4 \mathrm{~h}$, in the intact rat results in irreversible changes terminating in resorption of the fetus (Madhwa Raj \& Moudgal, 1970), the latter interpretation seems more feasible. While the mechanism by which vagotomy decreases $\mathbf{L H}$ concentration is not known, the present results suggest that the vagus may participate in the control of LH secretion during pregnancy via a neural feedback to the hypothalamus. Vagotomy does in fact inhibit the LH and FSH surge normally seen 5 h after unilateral ovariectomy (Burden \& Lawrence, 1977b). However, vagotomy may stimulate synthesis and/or secretion of some ovarian steroids other than progesterone which may inhibit LH release, as Hill (1962) reported that the denervated ovary produces larger amounts and more varied steroids than does the normally innervated ovary. The possibility that PGF decreases ovarian progesterone is ruled out by the finding that there is no change in ovarian PGF in the vagotomized animals. 


\section{PLATE I}
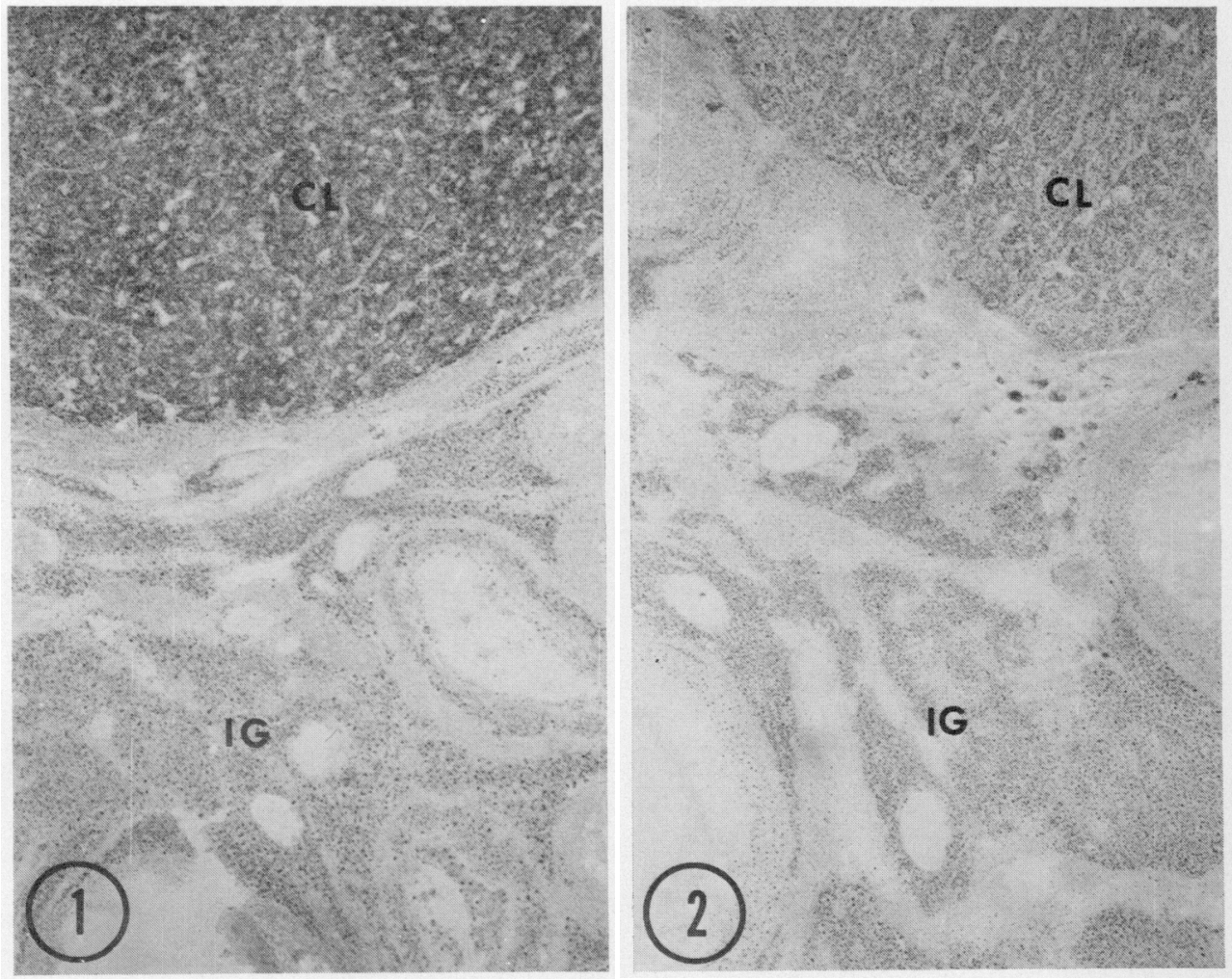

$\Delta^{5}-3 \beta$ Hydroxysteroid dehydrogenase activity with pregnenolone substrate in rat ovarian corpus luteum (CL) and interstitial gland (IG).

Fig. 1. Density of diformazan reaction product in sham-operated animal at Day 16 of pregnancy, $\times 120$.

Fig. 2. Vagotomy on Day 8 of pregnancy results in a decrease in density of diformazan reaction product by Day 16 of pregnancy. $\times 120$. 
Even though the absorbance values for the diformazan reaction product for the demonstration of $3 \beta$-HSD were not statistically significantly different, there was a definite trend towards less activity in the interstitial gland and corpora lutea of vagotomized rats, and a decreased ability to synthesize progesterone may be postulated and was reflected in the lowered amounts of ovarian and plasma progesterone in the vagotomized rats. $\mathrm{LH}$ is known to stimulate directly the activity of $3 \beta-\mathrm{HSD}$ (Rubin, Hillard, Hayward \& Deane, 1965; Rondell, 1974), and we suggest that the decreased LH levels in vagotomized rats lead to reduced $3 \beta$-HSD activity and therefore low plasma and ovarian progesterone levels. Vagotomy may, however, directly affect ovarian $3 \beta$-HSD activity. Adrenergic and cholinergic denervation of the rat ovary by mesovarian section or selected adrenergic denervation

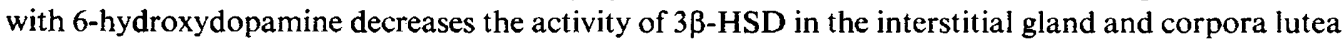
of rats at Days 10, 14 and 18 of pregnancy (Burden \& Lawrence, 1977a). While the results of mesovarian section may be explained by a sectioning of the vagus in this area, we find it difficult to explain the action of 6-hydroxydopamine. In the rat, ovarian nerves may have a dual function: vagal nerves may have a sensory role and modulate secretion of gonadotrophins via the hypothalamus and pituitary and adrenergic nerves may have a motor function and act through terminals in close apposition to steroid secreting cells (Lawrence \& Burden, 1976).

This study was supported by Grant HD 06899 from the National Institute of Child Health and Human Development, United States Public Health Service. We are indebted to Dr Vernon L. Gay, Department of Physiology, University of Pittsburgh, for the LH assays. Pure PGF- $2 \alpha$ standard and PGF antibody were kindly provided by Dr K. T. Kirton of the Upjohn Company, Kalamazoo, Michigan.

\section{References}

Blaha, G.C. \& LeavitT, W.W. (1970) The distribution of ovarian $\Delta^{5}-3 \beta$-hydroxysteroid dehydrogenase activity in the golden hamster during the estrous cycle, pregnancy, and lactation. Biol. Reprod. 3, 362368.

Brenner, P.F., Guerrero, R., Cekan, Z. \& Diczfalusy, E. (1973) Radioimmunoassay method for six steroids in human plasma. Steriods 22, 775-794.

Bulmer, D. (1965) A histochemical study of ovarian cholinesterases. Acta anat. 62, 254-265.

Burden, H.W. \& LAwrence, I.E., JR (1977a) The effects of denervation on the localization of $\Delta^{5}-3 \beta$-hydroxysteroid dehydrogenase activity in the rat ovary during pregnancy. Acta anat. 97, 241-247.

Burden, H.W. \& LaWrence, I.E., Jr (1977b) The effect of denervation on compensatory ovarian hypertrophy. Neuroendocrinology 23, 368-378

BurN, J.H. \& RAND, M.J. (1965) Acetylcholine in adrenergic transmission. A. Rev. Pharmac. 5, 163182.

Chaffee, V.M. (1974) Localization of ovarian acetylcholinesterase and butyrylcholinesterase in the guinea pig during the reproductive cycle. Am.J.vet. Res. 35, 91-95.

Challis, J.R.G., Davies, I.J. \& Ryan, J.K. (1973) The concentrations of progesterone, estrone and estradiol-17 $\beta$ in the plasma of pregnant rabbits. Endocrinology 93, 971-976.

HiLl, R.T. (1962) Paradoxical effects of ovarian secretions. In The Ovary, 1st edn, vol. 2, pp. 231-261. Ed. S. Zuckerman. Academic Press, New York.
Jacobowitz, D. \& Koelle, G.B. (1965) Histochemical correlations of acetylcholinesterase and catecholamines in postganglionic autonomic nerves of the cat, rabbit, and guinea pig. J. Pharmac. exp. Ther. 148, 225-237.

JaCOBowitz, D. \& WaLlach, E.E. (1967) Histochemical and chemical studies of the autonomic innervation of the ovary. Endocrinology 81, 1132-1139.

JORDAN, S.M. (1970) Adrenergic and cholinergic innervation of the reproductive tract and ovary in the guinea pig and rabbit. J. Physiol., Lond. 210, 115p$117 \mathrm{p}$.

KaRNovsky, M.J. \& Roots, L. (1964) A "DirectColoring" thiocholine method for cholinesterases. J. Histochem. Cytochem. 12, 219-221.

KoelLE, G.B. (1955) The histochemical identification of acetylcholinesterase in cholinergic, adrenergic, and sensory neurons. J. Pharmac. exp. Ther. 114, 167-184.

LAWrenCE, I.E., JR \& Burden, H.W. (1976) The autonomic innervation of the interstitial gland of the rat ovary during pregnancy. Am.J. Anat. 147, 81-94.

Madhwa RaJ, H.G. \& Moudgal, N.R. (1970) Hormonal control of gestation in the intact rat. Endocrinology 86, 874-889.

Morishige, W.K., PePe, G.J. \& Rothchild, I. (1973) Serum luteinizing hormone, prolactin, and progesterone levels during pregnancy in the rat. Endocrinology 92, 1527-1530.

Niswender, G.D., Midgely, A.R., JR, Monroe, S.E. \& REICHERT, L.E., JR (1968) Radioimmunoassay for rat luteinizing hormone with anti-ovine $\mathrm{LH}$ serum and ovine LH-131I. Proc. Soc. exp. Biol. Med. 128, 807811. 
RONDELL, P. (1974) Role of steroid synthesis in the process of ovulation. Biol. Reprod. 10, 199-215.

Rubin, B.L., Hilliard, J., Hayward, J.N. \& Deane, H.W. (1965) Acute effects of gonadotrophic hormones on rat and rabbit ovarian $\Delta^{5}-3 \beta$-hydroxysteroid dehydrogenase activities. Steroids, Suppl. 1, 121-130.
Stellflug, J.N., Louis, T.M., Hafs, H.D. \& Segun, B.E. (1975) Luteolysis, estrus and ovulation, and blood prostaglandin $F$ after intramuscular administration of 15,30 or $60 \mathrm{mg}$ prostaglandin $\mathrm{F}_{2 \mathrm{k}}$. Prostaglandins 9, 609-615.

Received 18 Novenber 1977 